Arqueología y Sociedad,

№ 20, 2009

\title{
OCUPACIÓN PREHISPÁNICA EN LA ISLA SAN LORENZO: Aportes del Proyecto ArQueológico Isla SAN Lorenzo
}

\author{
José Hudtwalcker Morán*
}

\begin{abstract}
Resumen
Las evidencias culturales registradas e investigadas por el Proyecto Arqueológico Isla San Lorenzo corresponden cronológicamente con el final del Intermedio Tardío y todo el Horizonte Tardío de nuestra cronología (siglos XV-XVI d.C.). La principal ocupación prehispánica se concentró en el extremo sureste de la isla, en la caleta de La Cruz, con la presencia de un gran cementerio y un asentamiento temporal con probables funciones de embarcadero y zona de viviendas. Es probable que el asentamiento sirviera como eje para las actividades económicas de explotación de recursos hidrobiológicos de la isla (mariscos, pesca y guano).

La presencia de fragmentos de spondylus, cuentas de piedra y concha, conchuela y objetos pequeños con representaciones de peces permiten plantear la hipótesis de ritos vinculados con el culto al mar y a las islas, así como con la "fertilidad" marina y los recursos presentes en la isla. La hipótesis sobre ritos propiciatorios al mar y a las islas se sustenta con las fuentes escritas de la colonia, principalmente con los textos del siglo XVI y XVII. Se puede afirmar que durante la época prehispánica la Isla San Lorenzo tuvo uso ritual y económico, las cuales fueron funciones integradas y complementarias entre sí.
\end{abstract}

\section{Palabras clave}

Proyecto Arqueológico Isla San Lorenzo, caleta de la Cruz, cementerio, mujer tejedora, asentamiento temporal, spondylus, ritos propiciatorios, función ritual y económica.

\begin{abstract}
The cultural evidences registered and investigated for the San Lorenzo Island Archaeological Project suggest that during island's prehispanic occupation, the main settlement concentrated on the southern tip of the island, at Caleta de la Cruz. There, a temporary fisher's camp - and/or guano collectors -- and a cemetery were found. Chronologically, this occupation dates from the end of the Late Intermediate Period through the whole Late Horizon (XV - XVI Centuries A.D.).

The presence of spondylus's fragment and other objects with representations of fishes suggests rites with the cult to the sea and the islands, as well as with the "marine fertility". The hypothesis of rites to the sea and the islands is sustained with the written sources of the colony, mainly with texts of century XVI and XVII. It is possible that during the prehispanic time the San Lorenzo island had ritual and economic use, which were integrated and complementary functions to each other.
\end{abstract}

\section{Keywords}

San Lorenzo Island Project, caleta de la Cruz, cementery, weaver woman, temporary settlement, propitiatory rites, ritual and economic functions.

\footnotetext{
* Licenciado en Arqueología de la Pontificia Universidad Católica del Perú. Es miembro ordinario del Instituto Riva Agüero-PUCP. Ha trabajado en la Dirección de Investigaciones del Instituto Nacional de Cultura. Con experiencia en investigación arqueológica en el Perú, especialmente en sitios del litoral y en arqueología subacuática. Desde el año 2003 al presente realiza investigaciones arqueológicas e históricas en la isla San Lorenzo. Durante los años 2004 al 2008 trabajó como asesor en la Dirección de Intereses Marítimos e Información de la Marina de Guerra del Perú Correo electrónico: cucho379@yahoo.es / website: www.islasdelperu.com
} 
El Proyecto Arqueológico Isla San Lorenzo (PAISL) es promovido por la Dirección de Intereses Marítimos e Información de la Marina de Guerra del Perú. Al presente, el PAISL lleva seis años de investigación científica en la isla. El artículo se centra en las evidencias culturales durante la época prehispánica de la historia ocupacional de la isla.

\section{MARCO GEOGRÁFICO}

Ubicada frente al litoral limeño, la isla San Lorenzo junto con la isla El Frontón y los islotes Cabinzas, Palominos y la Peña Horadada, conforman el grupo de Islas del Callao. San Lorenzo es la de mayores dimensiones del grupo y la de mayor tamaño en nuestro litoral. (Fig. 1).

Está conformada por un grupo de cuatro cerros, distribuidos de Norte a Sur de la siguiente manera, el Cabezo, la Mina o del Cañón, Encantado y Guanay. Éstos forman una especie de espinazo a todo lo largo de la isla, siendo el de mayor altitud el cerro La Mina con 398 m.s.n.m.

Su disposición geográfica, paralela a las costas de Lima, determina la existencia de dos flancos, el Protegido y el Expuesto. El Protegido es el flanco que mira al litoral de Lima y el Callao, cuenta con playas mansas y de fácil desembarco. El Expuesto es el flanco que mira a la corriente marina, cuenta con playas bravas e impredecibles, siendo casi imposible el desembarco. El flanco protegido es el que presenta las mejores condiciones para la habitabilidad humana. Ambos flancos presentan excelentes recursos hidrobiológicos, los mismos que son explotados desde tiempos prehispánicos hasta nuestros días. Como todas las islas del litoral peruano, San Lorenzo es una isla árida y no existen fuentes de agua dulce.

\section{AnTECEDENTES}

Como antecedentes de la investigación del PAISL se tiene los siguientes trabajos:
1. Investigaciones de Max Uhle (19061907), cuya colección se encuentra depositada en el Museo Nacional de Arqueología, Antropología e Historia del Perú.

2. Catastro Arqueológico del Valle del Rímac, ejecutado por el Instituto Riva Agüero de la Pontificia Universidad Católica del Perú (IRA-PUC) por encargo del Instituto Nacional de Cultura (1974).

3. Estudio de los metales de la colección Uhle por Marcela Ríos y Enrique Retamozo (1978).

4. Estudio de una parte de los objetos cerámicos de la colección Uhle por Johny Isla (1995).

5. Prospección Arqueológica de la Isla por el Instituto Riva Agüero-Pontificia Universidad Católica en convenio con la Marina de Guerra del Perú (1999).

\section{EL PAISL y LA OCUPACIÓN PREHISPÁNICA}

La ocupación principal durante la época prehispánica se concentró en el extremo meridional del flanco protegido de la isla, en la caleta de La Cruz. (Fig. 2). En esta caleta se encuentra un cementerio y un asentamiento temporal de poblaciones de pescadores y marisqueros, sin descartar la recolección de guano de la isla.

El Cementerio presenta dos sectores diferenciados no sólo geográficamente, sino en cuanto a los patrones de enterramientos. El primero, denominado como Cementerio Grande, con enterramientos profundos de individuos en posición fuertemente flexionada y con presencia de ajuares funerarios "ricos". El segundo, denominado como Cementerio Pequeño, con enterramientos poco profundos de individuos en posición extendida y con ajuares funerarios "simples".

El PAISL excavó durante el año 2004, diez contextos funerarios en ambos sectores, siete 


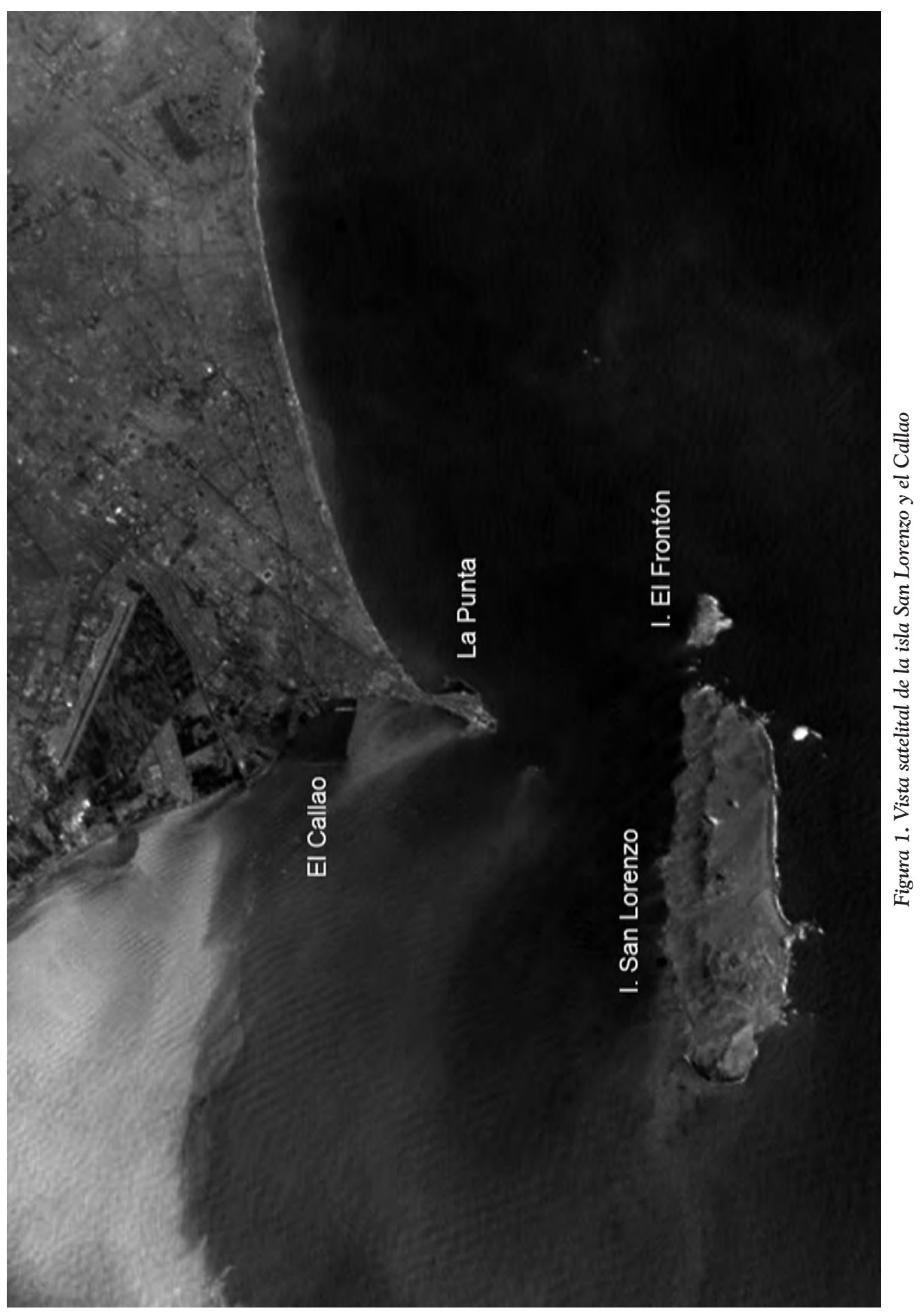




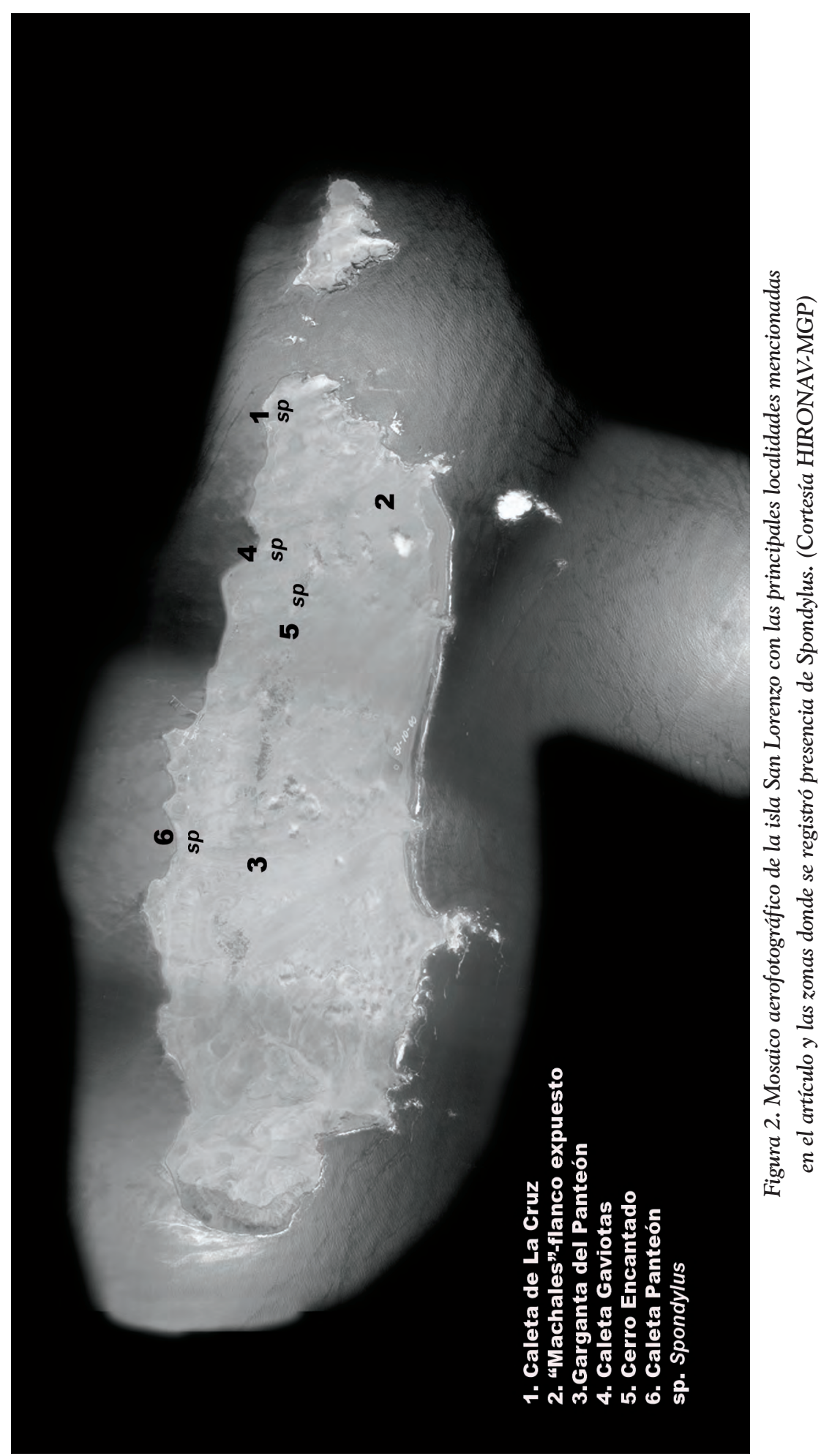




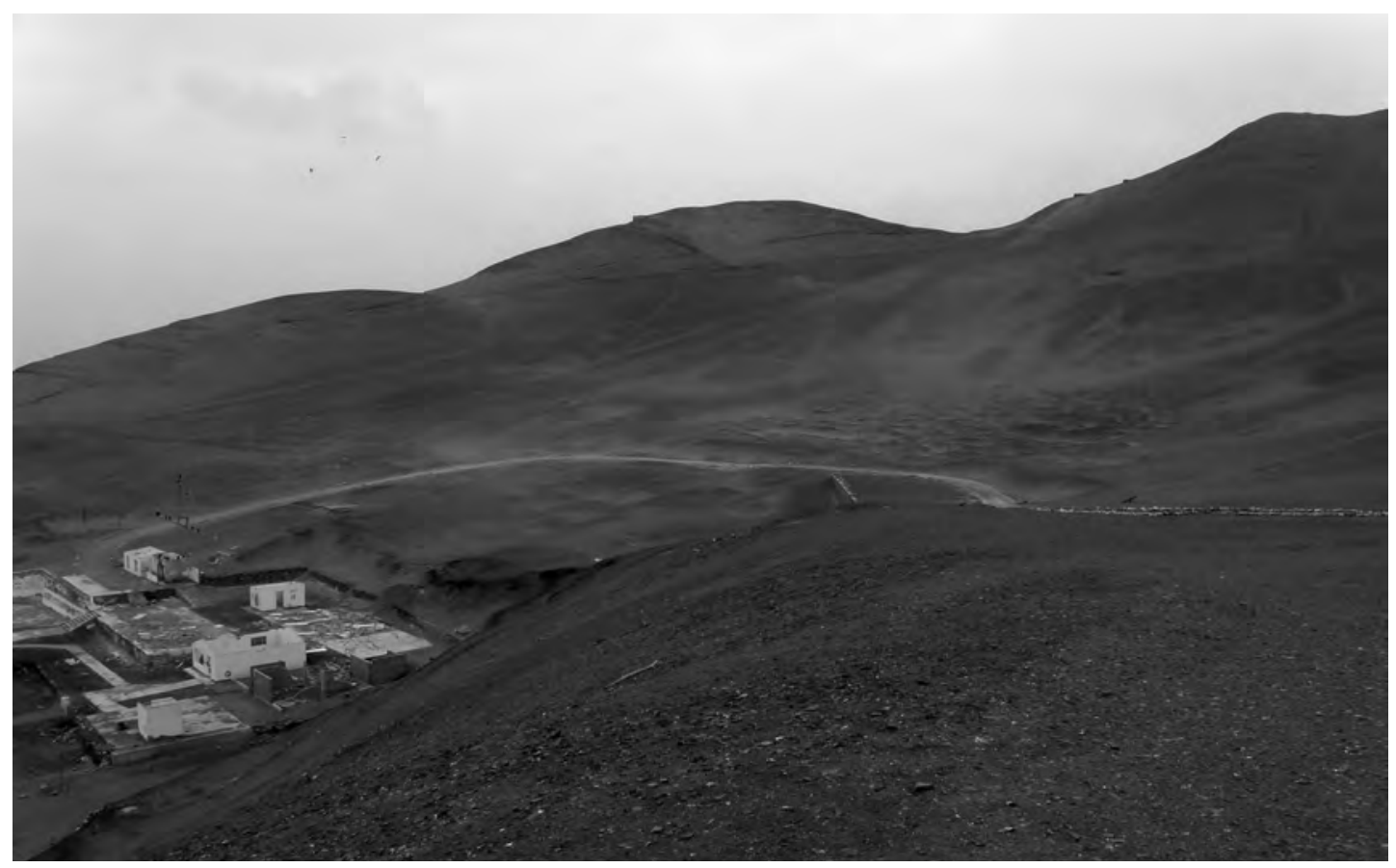

Figura 3. Caleta de La Cruz

en el grande y tres en el pequeño. La totalidad de los contextos registrados presentaron disturbamiento. El contexto funerario Entierro VIII, excavado en el cementerio grande, representa un caso de enterramiento de una mujer dedicada a la manufactura de finos textiles probablemente empleados durante las ceremonias y rituales (Figs. 4 al 10). Los materiales culturales asociados con los entierros corresponden con los estilos presentes durante el Horizonte Tardío de nuestra cronología, estos son Ichma, Chimú, Chimú-Inca, Inca, Chancay Negro sobre Blanco y Chincha. Asimismo, las excavaciones del proyecto permitieron recuperar una pequeña pero representativa colección de textiles. La hipótesis respecto al cementerio, es que correspondió a un área de enterramiento para personas vinculadas ritualmente con la isla (como pacarina o lugar de origen), uno de estos grupos serían las mujeres dedicadas a las actividades textiles,

Figura 4. Contexto Funerario Entierro VIII

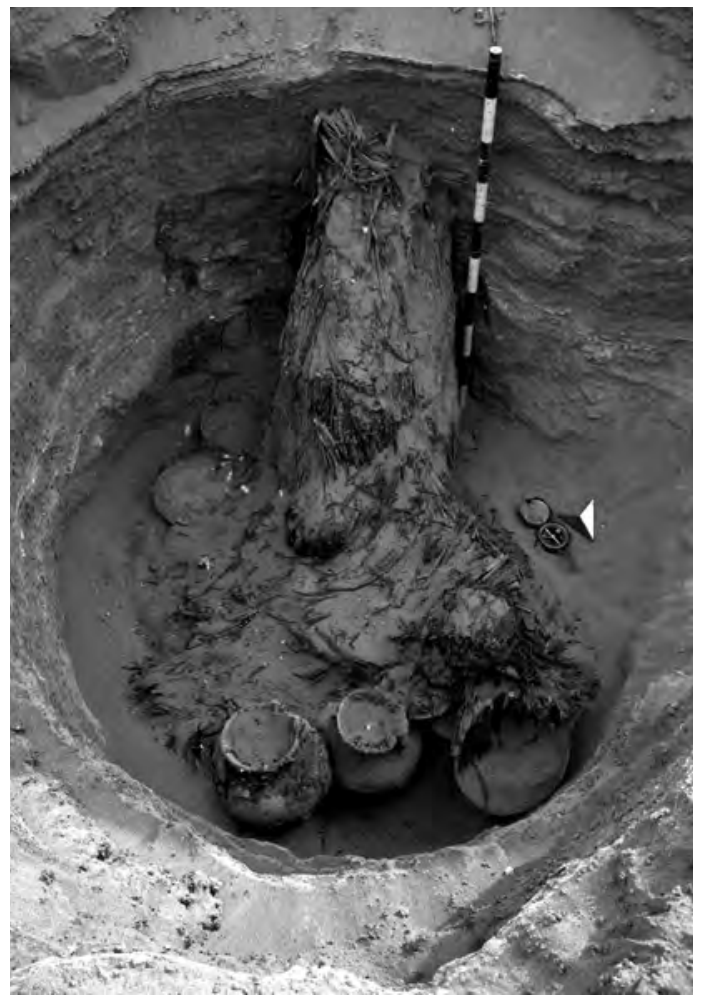




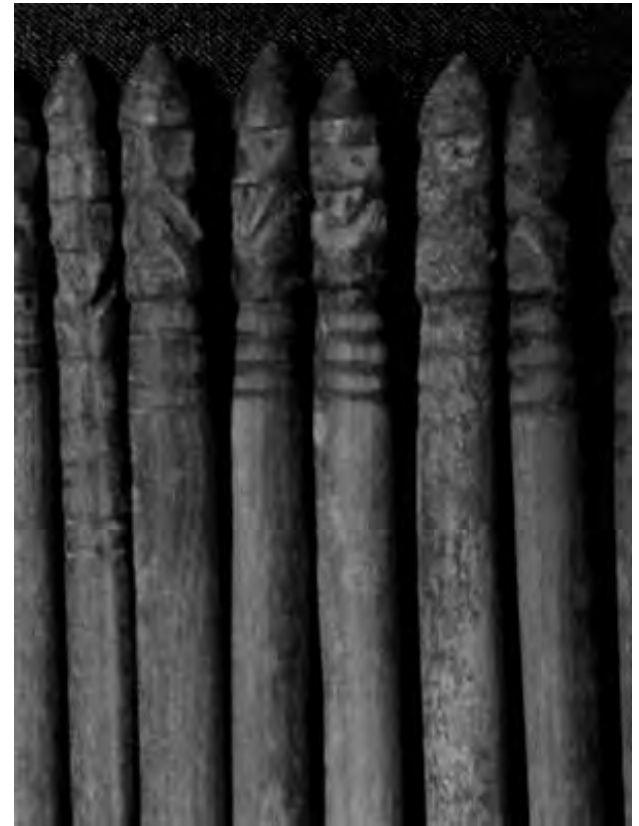

Figura 8. Instrumental para textilería asociado con el Entierro VIII

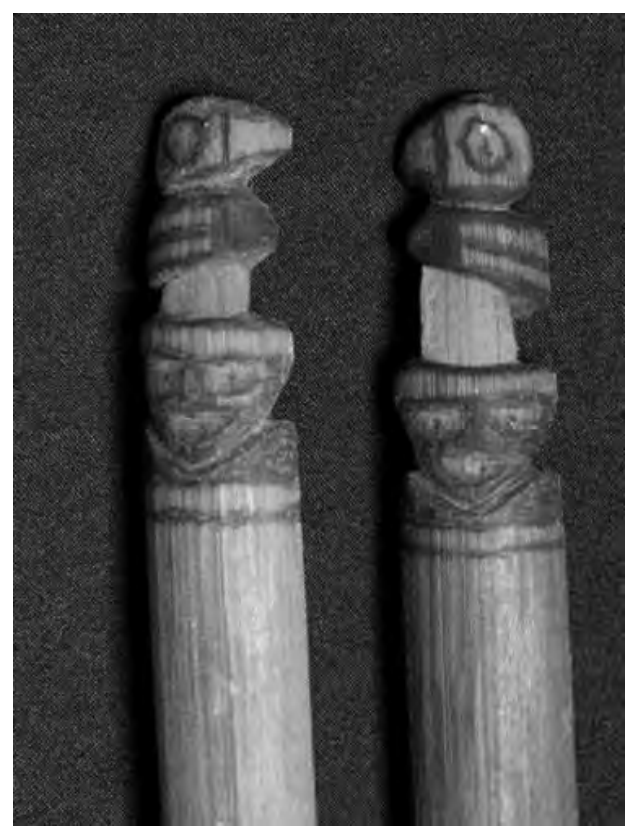

Figura 9. Espadas asociadas con el Entierro VIII

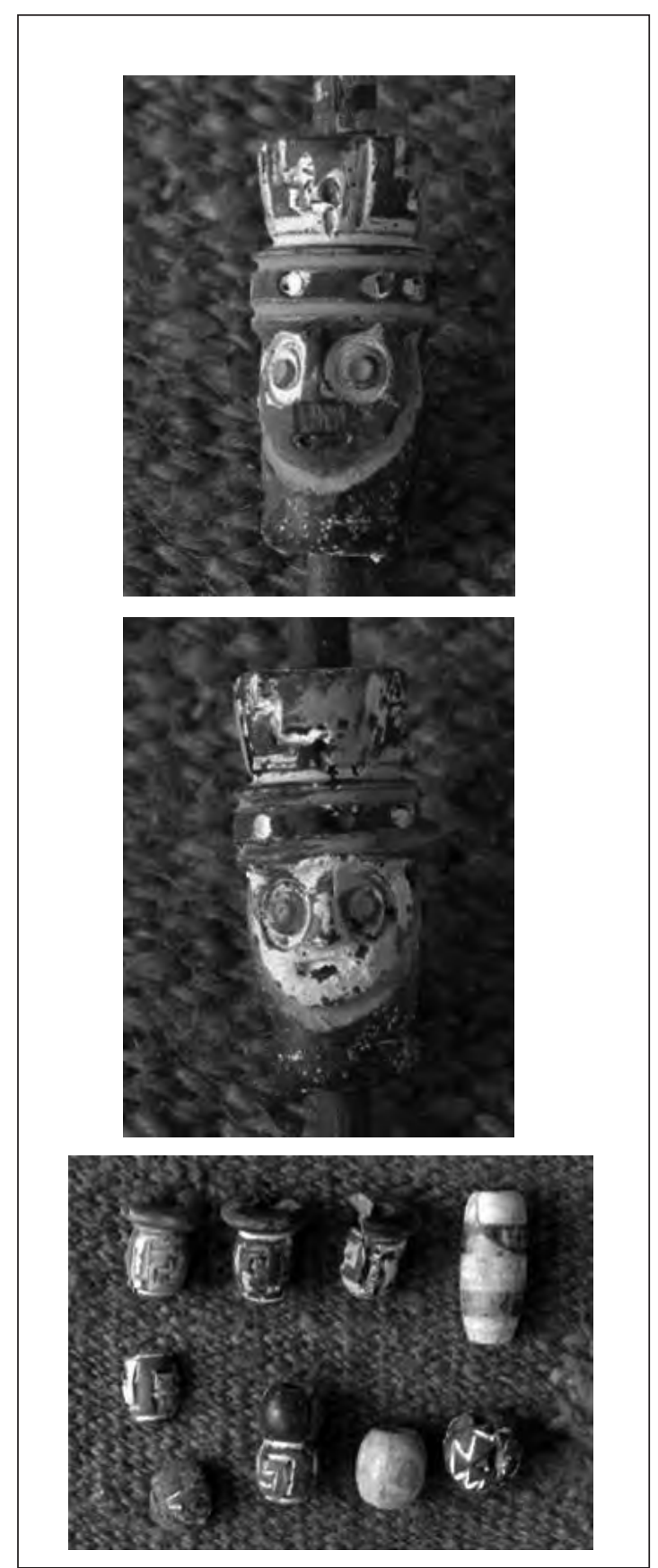

Figuras 5, 6 y 7 .

Piruros asociados con el Entierro VIII 


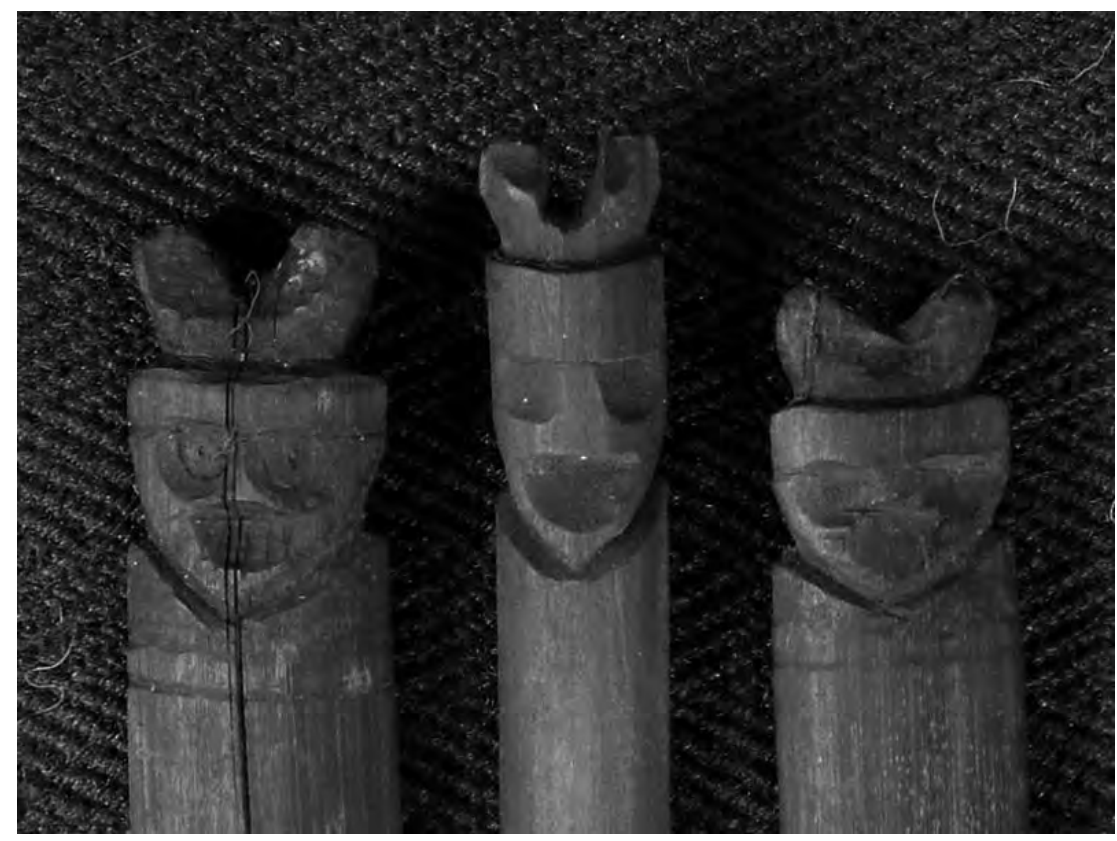

Figura 10. Espadas asociadas con el Entierro VIII.

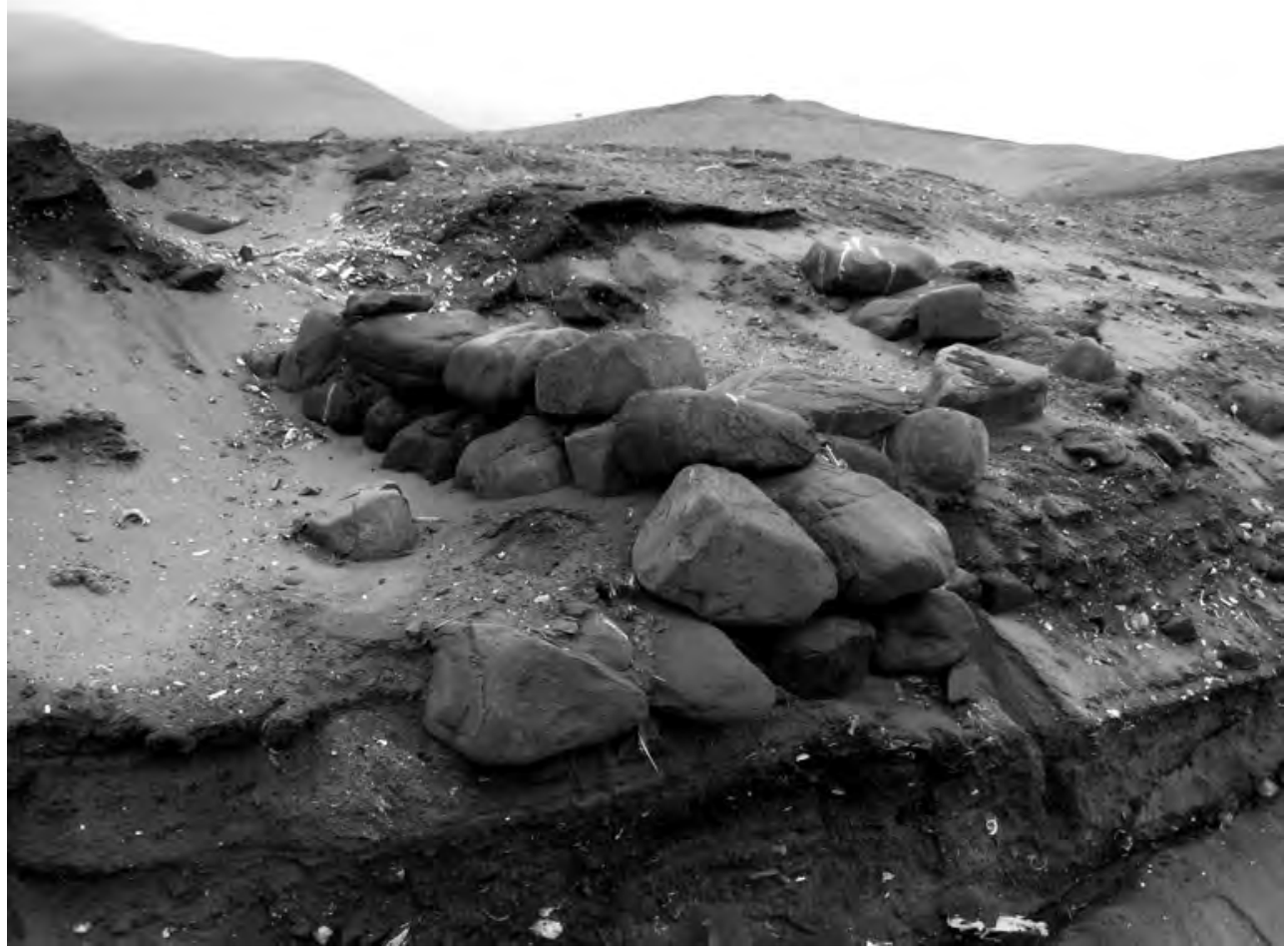

Figura 11. Asentamiento temporal en caleta de La Cruz. 
procedentes probablemente del Complejo Arqueológico de Armatambo.

El Asentamiento temporal colinda con el Cementerio Grande y debido a la fuerte destrucción del sitio sólo se realizó la limpieza de un perfil expuesto. (Figs. 11 y 12). Se registraron los restos de terrazas de piedra, elaboradas con cantos de playa, así como, de restos de paredes de cañas. Se pudo registrar in situ los restos de una vasija cerámica para contener líquido (chicha o agua). Los restos de basura depositados en sus diferentes niveles de ocupación, corresponden en su mayoría a una dieta en base a los recursos proporcionados por la isla (moluscos, aves marinas y peces). La hipótesis respecto al asentamiento, es que cumplió con las funciones de embarcadero y puerto principal de las poblaciones prehispánicas que explotaron los recursos hidrobiológicos de la isla. El material cerámico corresponde con las vasijas utilitarias Ichma asociadas al Horizonte Tardío.
Otro grupo de evidencias de actividades humanas prehispánicas registradas fuera de la caleta de La Cruz, corresponden a los restos de campamentos y conchales extensos, distribuidos principalmente en dos zonas.

La primera, ubicada en la zona meridional del flanco expuesto de la isla, es una extensa área con presencia de basurales, restos de artefactos líticos y algunas estructuras de piedra a manera de habitáculos, en ella se registraron los restos de actividades vinculadas con la explotación del molusco conocido como "macha" (Mesodesma). (Fig. 13). La segunda se ubica a lo largo de la garganta del Panteón en su conexión con las pampas de arena sobre Playa Grande y las faldas medias del cerro La Mina, en esta zona se encuentran los restos de basurales y algunas estructuras de piedra, de características similares a las registradas en la primera zona. Se trataría de campamentos temporales de pescadores, que utilizaron dicha área como zona de tránsito

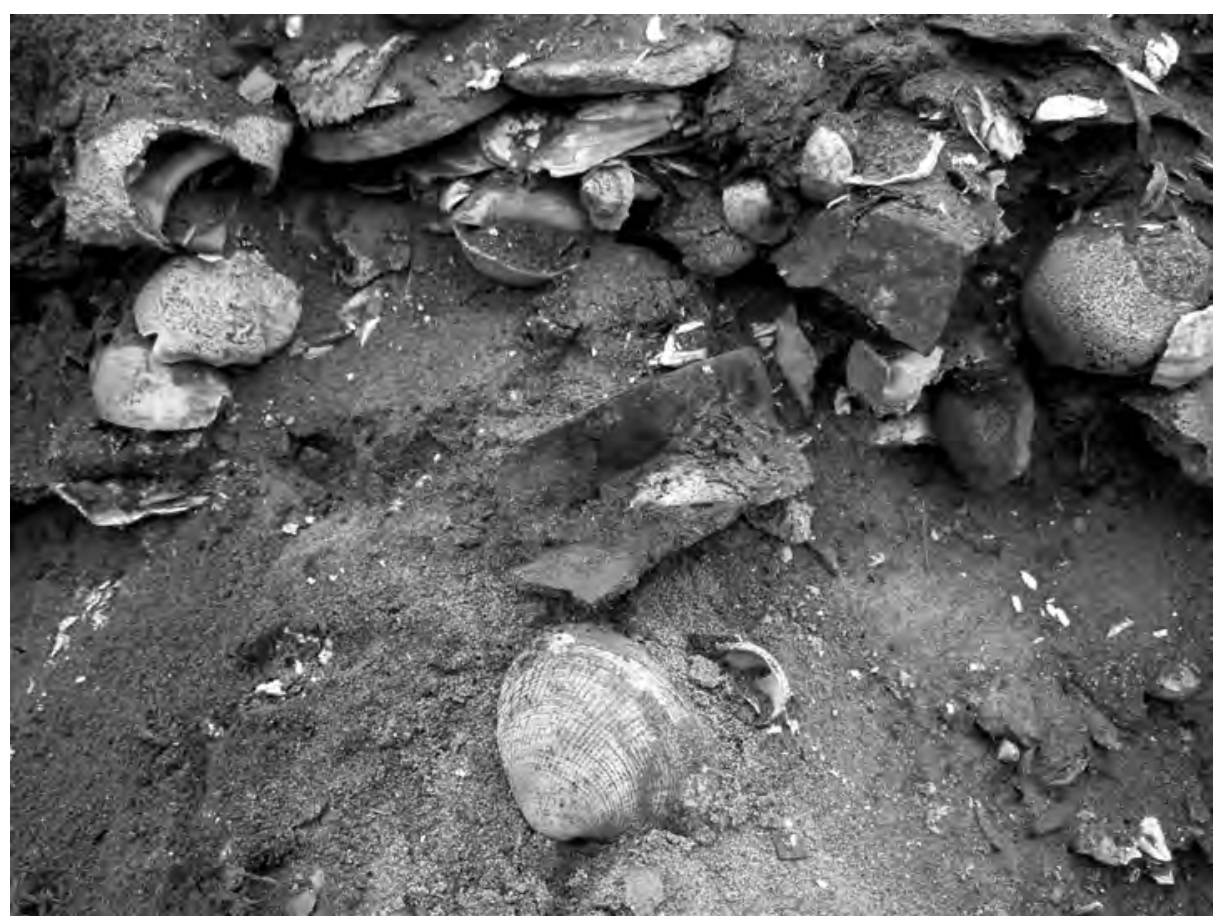

Figura 12. Asentamiento temporal en caleta de La Cruz -restos orgánicos- 


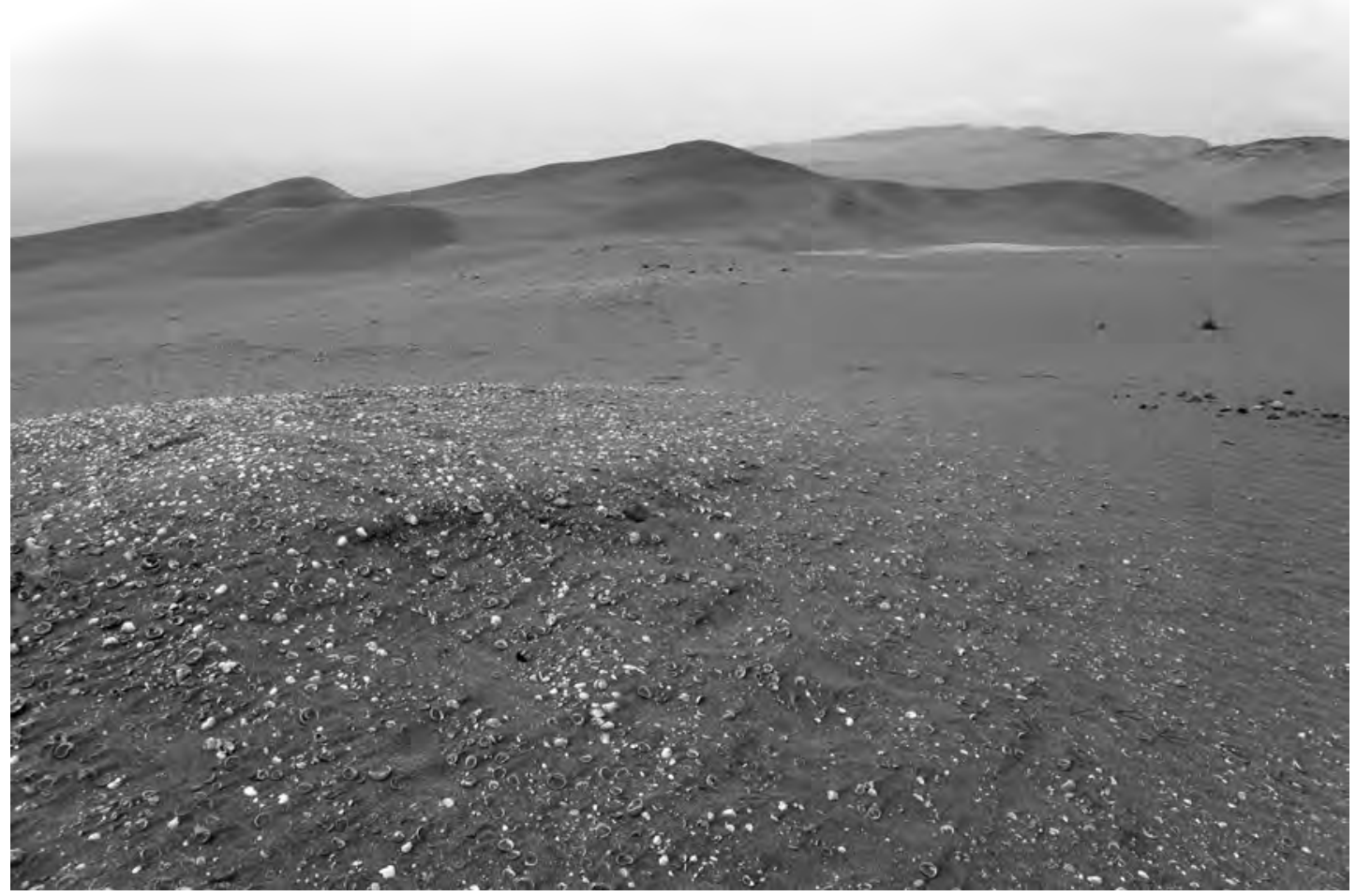

Figura 13. Conchales extensos en el flanco expuesto de la isla con restos de explotación de la "macha" (Mesodesma). A este grupo de conchales se está denominando como "machales".

desde el flanco protegido hacia el expuesto.

La ausencia de fragmentos de cerámica u otro material diagnóstico en los conchales, no son argumentos suficientes para sustentar que éstos corresponden cronológicamente con el periodo precerámico. Al presente, no se cuentan con fechados absolutos para dichos conchales.

Un tema que incluye la investigación del PAISL es el estudio integral de la colección recuperada por Max Uhle en la isla, dicha colección se guarda en los depósitos del Museo Nacional de Arqueología, Antropología e Historia del Perú. Al presente, se está realizando el estudio preiconográfico del gran manto pintado de algodón, de más de ocho metros de largo, recuperado por el investigador alemán durante sus trabajos en el cementerio prehispánico de caleta de La Cruz.
Presencia de Spondylus y evidencias de PROBABlES RITOS PROPICIATORIOS

Se registró presencia de Spondylus en varios sitios de la isla. Particularmente, en asociación con estructuras aisladas de piedra en la caleta Gaviotas (Fig. 14) y en el nivel inferior de la cima del cerro Encantado. Estas estructuras se encuentran muy destruidas por lo que es difícil definir sus características y dimensiones con mayor precisión. Presentan en su construcción cantos de playa junto con areniscas semi canteadas. El uso de piedras específicamente traídas desde la orilla de playa es una característica tecnológica del diseño arquitectónico prehispánico en la isla.

Asociadas con estas estructuras, se encontraron evidencias de probables ritos vinculados con el culto al mar y las islas. Estas consisten en la pre- 


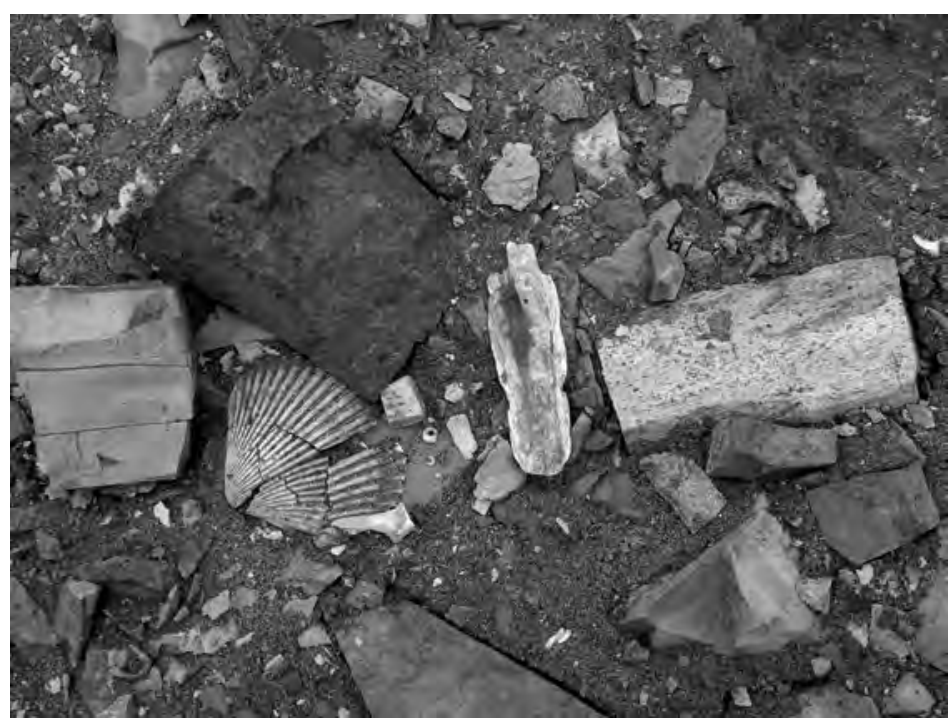

sencia de fragmentos de Spondylus (concreciones, cuentas, nódulos, petos, así como restos de las espinas o uñas de la concha) junto con otros materiales, como pequeños fragmentos de laminillas de cobre, cuentas y un fragmento de una piedra de color verde turquesa, llama la atención una pequeña figura tallada en dicha piedra con la representación de un pez. (Fig. 15). Asimismo, también se registró concentraciones de conchuela, compuesta por una gran cantidad y variedad de restos de conchas marinas erosionadas, en estas concentraciones de conchuela también habían fragmentos de laminillas de cobre, una pequeña laminilla de cobre

Figura 15. Piedra de color verde turquesa con la representación tallada de un pez, encontrada en el interior de la misma estructura en caleta Gaviotas donde se encontró los fragmentos de Spondylus como ofendas propiciatorias.
Figura 14. Fragmentos de Spondylus en el interior de una estructura en caleta Gaviotas.

Durante los trabajos de excavación en el cementerio prehispánico de caleta de la Cruz, en el sector grande, se encontraron valvas disturbadas de este molusco en la superficie del cementerio. La tomografía del fardo funerario Entierro VIII mostró que en el interior del mismo, a la altura de la parte posterior de la base del cráneo del individuo enfardelado, se depositó un especimen completo de dicho molusco. Lo que nos indica que el bivalvo fue parte del ajuar funerario directamente asociado a los individuos enterrados en este sector del cementerio. Así mismo, durante las excavaciones en la caleta del Panteón, en la parte noreste de la isla, se registró cuentas de Spondylus aisladas, probablemente estas fueron

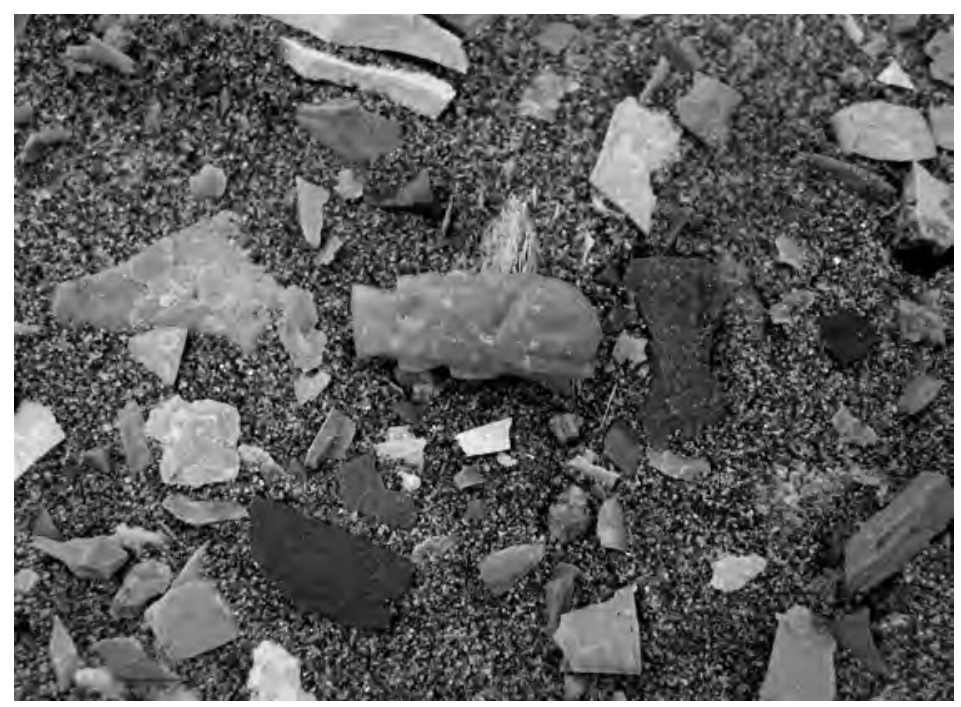




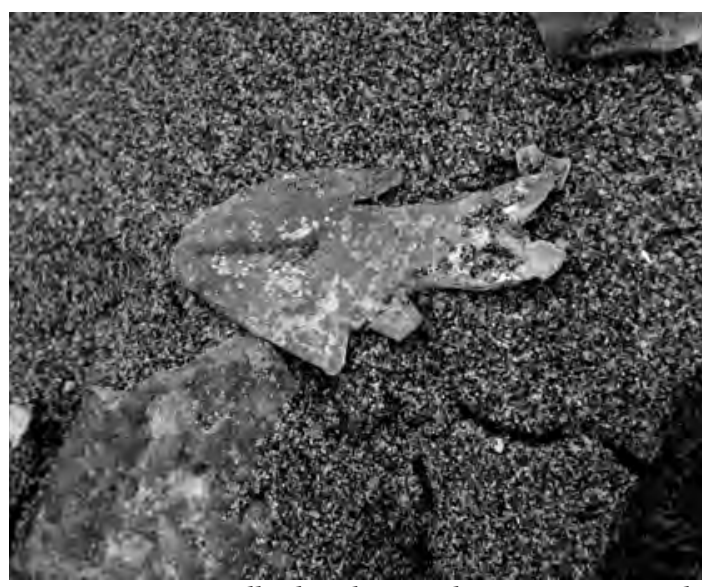

Figura 16. Laminilla de cobre con la representación de un pez encontrada en las faldas superiores del cerro Encantado muy cerca de la conchuela dispersa. (*)

parte de los accesorios del ornato personal de los pobladores prehispánicos que circularon por dicha zona.

Las evidencias descritas anteriormente indican que los bivalvos completos fueron parte del rito funerario y que los objetos elaborados en base a esta concha, como las cuentas de collar, fueron parte de los accesorios personales del poblador prehispánico. La bibliografía arqueológica que registra esta clase de evidencias es amplia y no deja mayores dudas respecto a las funciones mencionadas, mas no lo es en el caso de evidencias arqueológicas del uso de la concha Spondylus en ritos propiciatorios. Por fuentes etnohistóricas se sabe que el Spondylus fue considerado el alimento de los dioses y utilizado en los rituales y ofrendas, pero proveniente de las exploraciones o excavaciones arqueológicas todavía la información es reducida. En tal sentido, los recorridos arqueológicos sistemáticos realizados durante los últimos meses del año 2008 en la caleta Gaviotas y en la cima del cerro Encantado permitieron registrar evidencias razonables para plantear la hipótesis de actividades rituales propiciatorias.

\section{BALANCE FINAL}

Luego de presentar los alcances del PAISL con respecto a la ocupación prehispánica de la isla y las evidencias de probables ritos propiciatorios registrados en algunos sectores, se procederá a esbozar el balance final.

1. La principal ocupación prehispánica se concentró en el extremo sureste de la isla, en la caleta de La Cruz, con la presencia de un gran cementerio y un asentamiento temporal con probables funciones de embarcadero y zona de viviendas. Es probable que el asentamiento sirviera como eje para las actividades económicas de explotación de recursos hidrobiológicos de la isla (mariscos, pesca y guano).

2. La presencia en caleta Gaviotas y en la cima del cerro Encantado de contextos en superficie con Spondylus, cuentas dispersas de piedra y concha, conchuela y objetos pequeños con representaciones de peces, asociados con estructuras no domésticas y grandes rocas, permiten plantear la hipótesis de ritos vinculados con el culto al mar y a las islas, así como de ritos propiciatorios vinculados con la "fertilidad" marina y los recursos hidrobiológicos presentes en la isla. El registro arqueológico de este tipo de evidencias para otros sitios del litoral peruano es reducido y carecen de contexto, por lo tanto, los datos presentados representan un eslabón importante en la cadena de interpretación. La hipótesis sobre ritos propiciatorios al mar y a las islas se sustenta con las fuentes escritas de la colonia, principalmente con los textos de los siglos XVI y XVII.

3. Las evidencias culturales registradas e investigadas por el Proyecto Arqueológico Isla San Lorenzo corresponden cronológi-

(*) Las fotografías 3, 11 al 16 pertenecen al autor y las fotografías 4 al 10 a José Pinilla. 
camente con el final del Intermedio Tardío y todo el Horizonte Tardío de nuestra cronología (siglos XV-XVI). No se niega la posibilidad de la existencia de evidencias prehispánicas para períodos anteriores a los indicados, pero probablemente éstas fueron tan poco significativas que no han dejado impacto, limitando los indicios que sugieran ocupaciones anteriores a la época indicada.

4. En resumen, se puede afirmar que durante la época prehispánica la isla San Lorenzo tuvo uso ritual y económico, las cuales fueron funciones integradas y complementarias entre sí.

\section{BiBLIOGRAFÍA}

Calancha, Antonio de la

1976/1638 Crónica moralizadora del orden de San Agustín en el Perú. 6 tomos. Lima. Edición de Ignacio Prado.

Cobo, Bernabé

1958/1653 Historia del Nuevo Mundo. Madrid. Biblioteca de autores españoles.

\section{Cárdenas, Mercedes}

2000 Resultados de la prospección arqueológica en la isla San Lorenzo. Informe presentado al Instituto Nacional de Cultura. Lima.

Huapaya, Cirilo y Lorenzo Roselló

1975 "Informe preliminar sobre sitios sin cerámica en la isla San Lorenzo". Boletín del Seminario de Arqueología del Instituto Riva Agüero-PUC, № 15-16, Publicación № 98. Lima.

Hudtwalcker, José y José Pinilla

2004a Cementerios en la isla San Lorenzo. Informe final al Instituto Nacional de Cultura de la segunda temporada de excavaciones. Lima.

2004b "Proyecto Arqueológico San Lorenzo 2003-2004". Revista de Marina, Año 97, № 2. Lima. DIMINMAR.
2005 "Puerto y cementerio Ichma en el complejo histórico arqueológico de caleta de La Cruz". Revista de Marina, Año 98, № 2. Lima. DIMINMAR

Hudtwalcker, José

2008 "Las islas del Callao en los albores del siglo XX: apuntes para su historia". Revista de Marina, Año 101, № 3. Lima. DIMINMAR.

2009 "Geografía y paisaje de la isla San Lorenzo". Revista de Marina, Año 102, № 1. Lima. DIMINMAR.

Isla, Johny

1995 "Materiales recuperados por Max Uhle (1906-1907) en la isla San Lorenzo, costa central del Perú". Gaceta Arqueológica Andina, № 24. Lima. INDEA.

Retamozo, Enrique y Marcela Ríos

1978 "Objetos de metal procedentes de la isla San Lorenzo". Arqueológicas, № 17. Lima. Museo Nacional de Antropología y Arqueología.

Uhle, Max

1907 "Hallazgos arqueológicos en la isla San Lorenzo". El Comercio. Lima. 